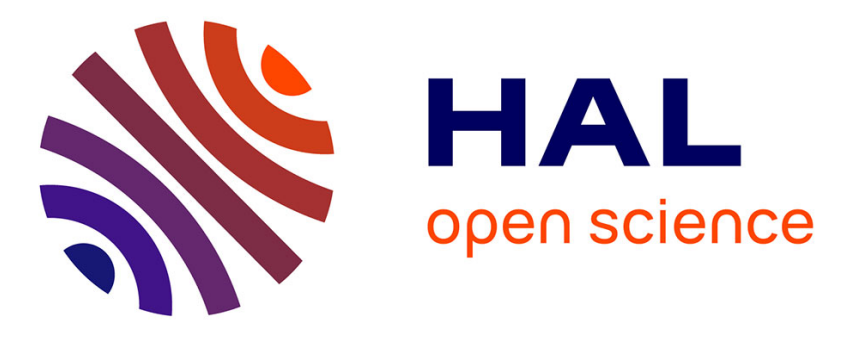

\title{
Learning cultural heritage by serious games
}

Michela Mortara, Chiara Eva Catalano, Francesco Bellotti, Giusy Fiucci, Minica Houry-Panchetti, Panagiotis Petridis

\section{To cite this version:}

Michela Mortara, Chiara Eva Catalano, Francesco Bellotti, Giusy Fiucci, Minica Houry-Panchetti, et al. Learning cultural heritage by serious games. Journal of Cultural Heritage, 2014, vol. 15 ( $\mathrm{n}^{\circ} 3$ ), pp. 318-325. 10.1016/j.culher.2013.04.004 . hal-01120560

\section{HAL Id: hal-01120560 https://hal.science/hal-01120560}

Submitted on 26 Feb 2015

HAL is a multi-disciplinary open access archive for the deposit and dissemination of scientific research documents, whether they are published or not. The documents may come from teaching and research institutions in France or abroad, or from public or private research centers.
L'archive ouverte pluridisciplinaire HAL, est destinée au dépôt et à la diffusion de documents scientifiques de niveau recherche, publiés ou non, émanant des établissements d'enseignement et de recherche français ou étrangers, des laboratoires publics ou privés. 


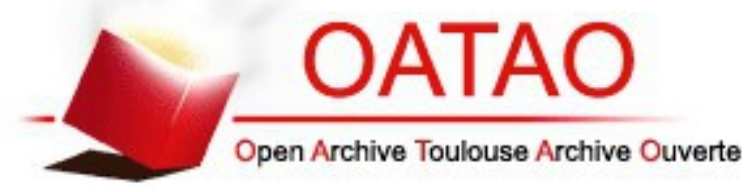

\section{Open Archive TOULOUSE Archive Ouverte (OATAO)}

OATAO is an open access repository that collects the work of Toulouse researchers and makes it freely available over the web where possible.

This is an author-deposited version published in : http://oatao.univ-toulouse.fr/ Eprints ID : 12664

To link to this article : DOI :10.1016/j.culher.2013.04.004 URL : http://dx.doi.org/10.1016/j.culher.2013.04.004

To cite this version : Mortara, Michela and Catalano, Chiara Eva and Bellotti, Francesco and Fiucci, Giusy and Houry-Panchetti, Minica and Petridis, Panagiotis Learning cultural heritage by serious games. (2014) Journal of Cultural Heritage, vol. 15 (n ${ }^{\circ}$ 3). pp. 318-325. ISSN 1296-2074

Any correspondance concerning this service should be sent to the repository administrator: staff-oatao@,listes-diff.inp-toulouse.fr 


\title{
Learning cultural heritage by serious games
}

\author{
Michela Mortara $^{\mathrm{a}, *}$, Chiara Eva Catalano ${ }^{\mathrm{a}, 1}$, Francesco Bellotti ${ }^{\mathrm{b}, 2}$, Giusy Fiucci ${ }^{\mathrm{c}, 3}$, \\ Minica Houry-Panchetti ${ }^{\mathrm{d}, 4}$, Panagiotis Petridis ${ }^{\mathrm{e}, 5}$ \\ a CNR-IMATI GE, via de Marini 6, 16149 Genova, Italy \\ ${ }^{\mathrm{b}}$ ELIOS Lab - DITEN, University of Genova, Via Opera Pia 11/a, 16145 Genova, Italy \\ ' ORT-France, 16, villa d'Eylau, 75116 Paris, France \\ d IRIT Lab, University of Toulouse III, 31062 Toulouse cedex 9, France \\ e The Serious Games Institute, Coventry University Technology Park, Innovation Village, Cheetah Road, Coventry, UK
}

\begin{abstract}
A B S T R A C T
Immersive technologies such as virtual environments and augmented reality have a clear potential to support the experiencing of cultural heritage by the large public, complementing the current tools and practices based on tangible goods such as museums, exhibitions, books and visual content. Serious games - videogames designed for educational objectives - appear as a new tool to learn cultural content in an engaging way. In this paper, we will provide an extensive portrait of the current proposition of serious games in the cultural sector, highlighting the educational objectives of games in this domain and analysing the complex relations between genre, context of use, technological solutions and learning effectiveness. We finally identify and discuss the most significant challenges in the design and adoption of educational games in cultural heritage.
\end{abstract}

\section{Research aims}

This paper aims at providing the state-of-the-art of serious games in the humanities and heritage field, highlighting the educational objectives of games in this domain and analysing the complex relations between genre, context of use, technological solutions and learning effectiveness.

\section{Introduction}

Virtual worlds have already been used in the cultural heritage field, allowing the broad public to appreciate remote (in space and time) cultural content with an immersive experience. This is the case of many virtual museum applications, which offer the opportunity of exploring in first person a remote site, manipulating fragile relics with no risk of damage, benefiting from additional

\footnotetext{
* Corresponding author. Tel.: +390106475669; fax: +390106475660. E-mail addresses: michela@ge.imati.cnr.it, michela.mortara@ge.imati.cnr.it (M. Mortara), chiara@ge.imati.cnr.it(C.E.Catalano), franz@elios.unige.it(F. Bellotti), giusy.fiucci@ort.asso.fr (G. Fiucci), Minica.Houry-Panchetti@irit.fr

(M. Houry-Panchetti),PPetridis@cad.coventry.ac.uk (P. Petridis).

${ }^{1}$ Tel.: +390106475669; fax: +390106475660.

2 Tel.: +390103532227 .

3 Tel.: +33620720283 .

${ }^{4}$ Tel.: +33562446449

${ }^{5}$ Tel.: +442476158251 .
}

multimedia information and following cross-correlations within the content, appreciating virtual reconstruction of damaged remains, and much more.

Although they are helpful, these applications still lack a powerful mechanism to engage the large public into an active state of learning where spectators are motivated to create their own knowledge rather than to receive information passively. Conversely, such engagement is evident in computer games providing amusing and compelling experiences, which keep the player focused for long lasting sessions. For this reason, games with educational purposes - namely Serious Games (SGs) - are now becoming more and more popular.

The main feature of a SG is its objective of supporting the player to achieve learning targets through a fun experience. The fun aspect of a SG provides engagement and can be determined by several factors like storyboard, graphics, usability, collaboration/competition mechanisms and interaction devices. The learning aspect implements a pedagogical approach, by structuring the educational content and organizing its presentation [1].

Thus, the design process of a SG differs from the one of a common e-learning application as an intrinsic balance between learning and gaming should be found. Indeed, the learning content in a SG has a predominant role in the game-play, but the game interactions and mechanics should not simply be a funny layer added atop a digital learning tool.

In this paper, we discuss the current situation of SGs in the cultural heritage field, presenting numerous examples of available 
games, primarily structured according to their learning objectives. SGs vary a lot not only in terms of learning objectives, but also of genre (e.g. adventure, simulation) and of application context (e.g. virtual visit), which impact game design. In the following, these three aspects (learning objective, genre and context) will be discussed while providing an extensive portrait of the current offer of serious games in the cultural sector. Up to our knowledge, Falk Anderson et al. [2] represents the only one attempt to sketch a stateof-the-art of serious games for cultural heritage, mainly focussing on the technological aspects. Our goal is tackling the application perspective, while providing a wider showcase including more recent developments. Moreover, on the basis of the overview, we also propose and discuss some key considerations for effective SG design.

In Section 3, a survey of the domain is proposed, which classifies 51 SGs for Heritage according to their main learning objective. In Section 4, the game genres are discussed with respect to their potential to transmit effectively the learning content. In Section 5, the specific requirements of the application contexts are described along with insights about the common practices and/or suggested improvements. Section 6 identifies two main SG design aspects, the game environment and the interaction modalities, and discusses their effectiveness to maximize engagement and deliver a proper cultural heritage experience. Finally, Section 7 summarizes opportunities, challenges and barriers to the adoption of SGs in the cultural sector and suggests research trends to enhance effectiveness of SGs.

\section{Serious game proposition in the cultural sector}

Cultural content is very diverse: on the one side, there is the physical, or "tangible", cultural heritage, such as historic sites and buildings, monuments, documents, works of art, machines, and other artefacts, which are considered worthy of preservation for the future. The natural environment is also an important factor of a society heritage. Natural heritage includes landscapes, flora and fauna, as well as geological, paleontological and morphological elements. Together with the architectonic and artistic legacy of a place, such elements are the target of cultural tourism, which is gaining increasing interest.

Nevertheless, there are many further factors which deeply characterize a culture and have a non-physical nature, namely the "intangible cultural heritage". These aspects include social values and traditions, customs and practices, philosophical values and religious beliefs, artistic expression, language and folklore. Intangible heritage is particularly difficult to preserve, and we believe SGs have the potential to maintain and communicate effectively, especially this immaterial legacy. Based on these considerations, we structured our analysis along a taxonomy featuring the following categories:

- cultural awareness;

- historical reconstruction;

- heritage awareness:

- artistic/archaeological heritage,

- architectural/natural heritage.

In the following, we describe each category along with brief descriptions of SGs tackling the corresponding educational objectives.

\subsection{Cultural awareness}

Cultural awareness is particularly focused on immaterial heritage, including the language, customs, traditions, spiritual beliefs, folklore and rules of behaviour in a society, without forgetting the influence of past events on that society. In these regards, SGs have the potential to recreate accurately non only a physical setting but rather: provide a holistic experience including sounds (spoken language, traditional music) and aesthetic elements; bring to life folkloristic and religious events; give the opportunity to practice in first person behavioural codes and habits through in-game tasks; and much more.

A significant representative of games for cultural awareness is Icura [3]. Playing the game and exploring the 3D realistic environment with soft traditional music played in the background, the player learns about Japanese culture and etiquette, which can raise cultural interest and support a real pre-trip planning. Similarly, Discover Babylon ${ }^{6}$, Roma Nova ${ }^{7}$ and Remembering 7 th $^{\text {Street }}{ }^{8}$, aim at raising awareness about ancient Mesopotamia's contribution to modern culture, ancient Rome and West Oakland in the time period post-World-War-II. Africa Trail $^{9}$ and Real Lives $2010^{10}$ simulate a 12,000 mile travel by bicycle through Africa or a different life in any country of the world (e.g. a peasant farmer in Bangladesh, or a computer operator in Poland), respectively. Recently, Huang and Huang [4] presented Papakwaqa, a serious game about the Atayal minority in Taiwan, particularly focussed on intangible cultural assets like tribal beliefs, customs, and ceremonies.

Some projects are supported by museums and include Yong's China Quest Adventure ${ }^{11}$ and The China Game ${ }^{12}$ about Chinese traditions and Fascinating Egyptian Mummies ${ }^{13}$ about the spiritual beliefs of the ancient Egyptians. Finally, The Great Bible Race ${ }^{14}$ deals with the religious roots of the Western civilization; The Mosaica project [5] developed a Jewish heritage game; Les Fromages de France ${ }^{15}$ advertises the variety of French cheeses and their geographical provenance.

\subsection{Historical reconstruction}

Games in this category have history as the primary educational goal and focus on the faithful reconstruction of a specific historical period, event or process which happened in the past; notions of archaeology, art, sociology and politics are also involved. Especially when dealing with the reconstruction of a specific process, it is usually important to involve the player actively in this event (like in a role-play game) to understand and learn the causes and the development of the event itself. For many events of the past, like historical battles, there is no physical remain but rather ancient textual descriptions only. In those cases especially, the recreation of the environment can give a concrete help to deliver knowledge of the past to the public in a more accessible way. When physical remains are available, they are usually reconstructed digitally in the environment to enrich the experience adding historically correct details.

As expected, many games in this category are set in a 3D environment. Very interesting examples of this kind are The Battle of Thermopylae [6] aiming to deliver the historical context and importance of the battle, the warfare of the opponents, their cultural differences and the strategic choices, and The Siege of Syracuse [7]

\footnotetext{
${ }^{6}$ http://www.fas.org/babylon/.

7 http://www.seriousgamesinstitute.co.uk/research.aspx?item=171\&section=14

8 http://7thstreet.org/.

9 http://www.mobygames.com/game/africa-trail.

10 http://www.educationalsimulations.com/products.html.

11 http://www.mylearning.org/yongs-china-quest-adventure-game-level-1/.

12 http://asiasociety.org/node/20787.

13 http://www.mcq.org/momies/index.html.

14 http://greatbiblerace.com/.

15 http://www.jeux-geographiques.com/jeux-geographiques-Les-fromages-deFrance-_pageid80.html.
} 
recreating the battlefield of the siege by the romans in $212 \mathrm{BC}$, where two players take the role of the opponent historical generals. Others are The ancient Olympia [8]; the Priory Herbert Undercroft, a reconstruction of the Benedictine monastery in Coventry, dissolved by Henry VIII [9]; Revolution [10], a role-playing game in the town of colonial Williamsburg during the American Revolution; The Playing History ${ }^{16}$ game series; George Washington's treasures ${ }^{17}$ and Rome in Danger ${ }^{18}$.

There are also some point-and-click adventures, like TimeMesh ${ }^{19}$, about some significant historic events of Europe (the Second World War, the maritime discoveries in the XV and XVI centuries and the industrial revolution), Signets of Power ${ }^{20}$ recreating the power struggle between the church, the nobility and the Crown in Aarhus, Denmark, depicted in 1458 and the Nat Geo Games Lost Chronicles series published by National Geographic (among the episodes: The fall of Julius Caesar, The mystery of Cleopatra ${ }^{21}$ and Salem).

Strategy games re-enacting famous historical battles are $1066^{22}$ The Battle of Waterloo ${ }^{23}$, and The Viking Quest ${ }^{24}$, while simulation games are: Expedition The Game ${ }^{25}$ about Stanley's journey to find Dr Livingstone; High Tea ${ }^{26}$ [11] set during the opium trade in China; the History Game Canada ${ }^{27}$ and Building Detroit ${ }^{28}$.

The Cat and the Coupe ${ }^{29}$ is a documentary game about the first democratically elected Prime Minister of Iran, Dr Mohammed Mossadegh. This game certainly takes an unusual approach to a genre mainly concerned with depicting reality: the environment is highly abstract and symbolic and the atmosphere is dreamlike and associative rather than realistic.

\subsection{Heritage awareness}

The majority of architectural/natural heritage awareness games either offer an immersive, realistic reconstruction of a real location to appreciate and learn the architectural, artistic or natural values of a site, or simply offer engaging mechanisms to motivate users into a real experience. The term virtual/augmented cultural tourism games is also used in this case [12] and includes the following games. Travel in Europe (TiE) is a prototype game organized as a set of treasure hunt games across European cities of art, where the stages are set in relevant cultural points of interest in a 3D reconstructed city [13]. Similarly, Streets of Culture ${ }^{30}$ allows users to drive in a virtual Liverpool around its main focal points and learn factual information through puzzles. The $80 D A Y S^{31}$ EU Project released an adventure game teaching geography.

Tidy City ${ }^{32}$ is a location-based game for smart phones that is played outdoors. The game consists in solving riddles about a specific city, which might require the player to explore places

\footnotetext{
16 www.playinghistory.eu.

17 http://www.washingtonsworld.org/washington.html.

18 www.thinkingworlds.com.

19 http://www.timemesh.eu/.

20 http://static.magtenssegl.dk/static/index.html?language=english

21 http://natgeo.trymedia.com/t_14th/s-1_3036_13607/AllGames/Hidden-Object/ Nat-Geo-Games-Mystery-of-Cleopatra.html.

22 http://1066game.com/.

23 http://www.bbc.co.uk//history/british/empire_seapower/launch_gms_battle waterloo.shtml.

24 www.bbc.co.uk/history/ancient/vikings.

25 http://www.history.com/shows/expedition-archived/interactives/expedition game.

26 http://hightea.wellcomeapps.com/.

27 http://www.historycanadagame.com/.

28 http://detroithistorical.org/buildingdetroit/building_detroit.php.

29 http://coup.peterbrinson.com/.

30 http://streetsofculture.com/.

31 http://www.eightydays.eu.

32 http://totem.fit.fraunhofer.de/tidycity.
}

never seen before while learning about the city's cultural heritage. Similarly, O' Munaciedd ${ }^{33}$, MediaEvo ${ }^{34}$ [14], VE-Game [15] and À la recherche de l'empreinte perdue ${ }^{35}$ (i.e. Seeking the lost footprint) are cultural treasure hunts for mobile devices set in Matera, Otranto, Venice (Italy) and Saint-Jean-Brévelay (France), respectively.

The only game really focussed on natural heritage we are aware of is WWF Panda Junior ${ }^{36}$, a WWF-endorsed game dedicated to the discovery of the African continent and wildlife to raise awareness about natural conservation.

In artistic/archaeological heritage awareness games, the player is in contact with the legacy of physical artefacts of a society, and learns about history, archaeology and art. Virtual museum games belong to this category. An example of this kind is Thiatro ${ }^{37}[16,17]$, a 3D virtual environment where the player acts as a museum curator, who has to arrange an exhibition on several topics collecting paintings from different virtual museums. To fulfil their task, players have to learn iconography, perspective, lighting and shading, the eras of Art, etc. Similarly, Middleton Mystery [18] is set in Belsay Hall, an English Heritage site and Bamiyan Valley in an Afghan archaeological site and aims at facilitating cooperation among international experts and local authorities responsible for the site management [19].

Other games in this category either aim at advertising real collections (e.g. My Culture Quest ${ }^{38}$ and Time Explorer ${ }^{39}$ ) or are actually integral part of a museum experience (e.g. The History of a Place ${ }^{40}$ at the Archaeological Museum of Messenia in Greece). Tate Trumps ${ }^{41}$ and Muse-Us [20] are two pervasive serious games for use in museums, running as smartphone applications; YouTell is about the battleship "G. Averof" and allows museum visitors to create and share through smart phones their own media and stories [21,22].

Finally, two games for archaeology: Dessine-moi un Mammouth (i.e. Let's draw a Mammoth!) and Multi-touch Rocks [23] dealing with the engravings in Gargas caves in the French Pyrénées ${ }^{42}$ and in Val Camonica, Italy, respectively.

In Fig. 1, a few examples of SGs in the different categories are depicted. In the next sections, we will discuss how such educational objectives relate to gameplay, meaning how a suitable genre is chosen in order to transmit the learning content effectively.

\section{Game genres in cultural heritage}

SGs in this domain appear in a wide variety of forms, spanning from trivia, puzzles and mini-games to engage in interactive exhibitions (e.g. History of a place, Multi touch Rocks) to mobile applications for museum or touristic site visits motivated by some reward/engagement mechanism (e.g. Muse-US, Tidy City), to simulations of past events (The battle of Waterloo) to adventures and role playing games set in faithful reconstructions or digital counterparts of real sites (e.g. the Priory Undercroft, Revolution).

While action games, as the most basic game genre, is one of the broadest form of entertainment games, it is not so for serious games in the cultural heritage domain. Actually, this is the least represented category. Action games require accurate and quick moves to

\footnotetext{
33 http://munaciedd.pa.itd.cnr.it/http://itunes.apple.com/us/app/omunaciedd/ id433862734? $\mathrm{mt}=8 \#$

34 http://www.mediaevo.unifg.it/.

35 http://www.oust-broceliande-vacances.com/broceliande-actualites/676-a-larecherche-de-lempreinte-perdue.html.

36 http://www.e-neko.com/?p=1491\&lang=en.

37 http://www.thiatro.info/.

38 http://www.mylearning.org/interactive.asp?journeyid=238\&resourceid=587.

39 http://www.britishmuseum.org/explore/young_explorers/play.aspx.

40 http://www.makebelieve.gr/mb/www/en/portfolio/museums-culture/54amm.html.

${ }^{41}$ http://www.hideandseek.net/tate-trumps/.

42 http://www.numerigrottes-pyrenees.fr/p-parcours-nestploriafr.html.
} 

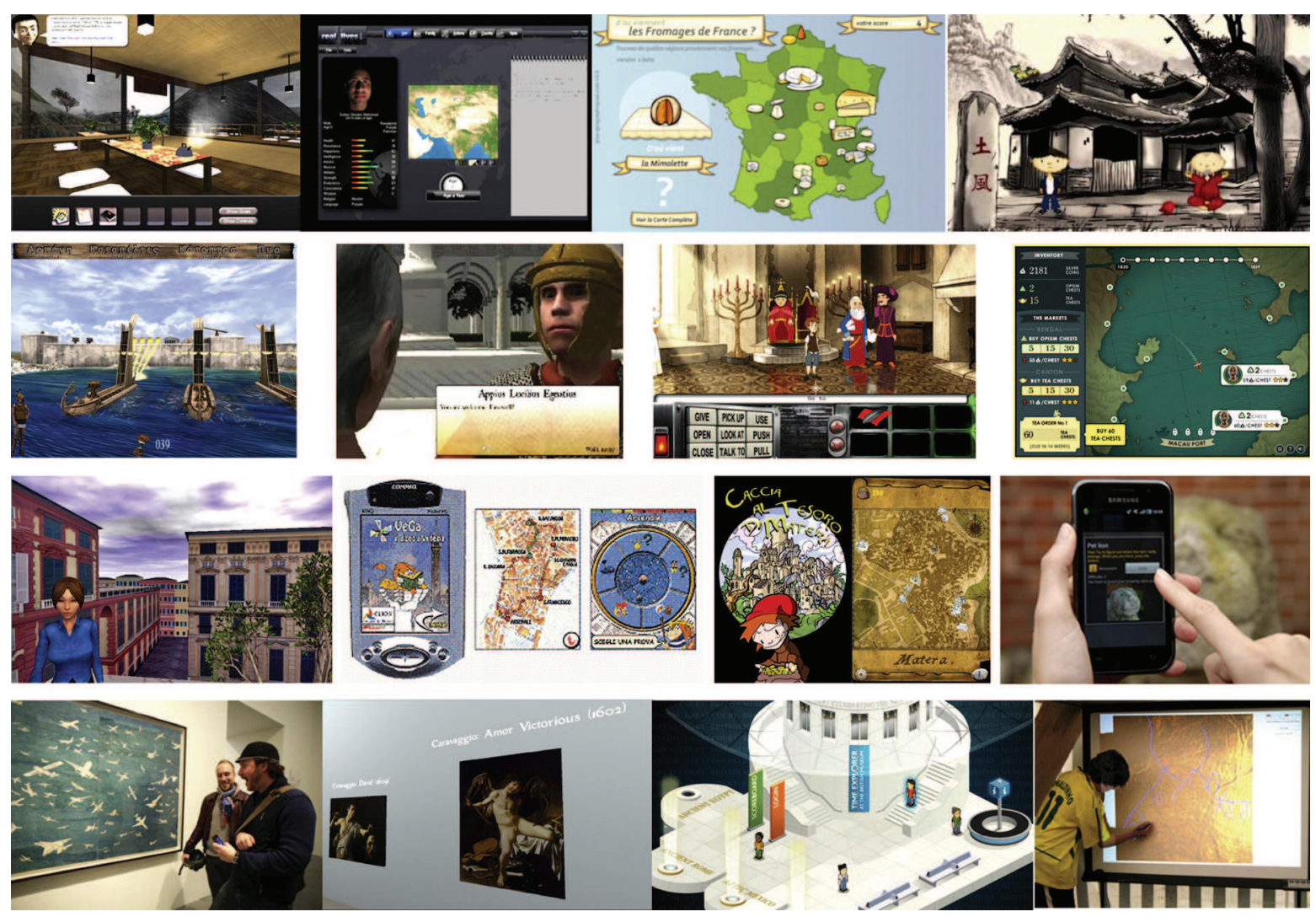

Fig. 1. From top to bottom, each row depicts representative serious games (SGs) for cultural awareness (Icura, Real Lives 2010, Les Fromages de France, Yong's China Quest), historical reconstruction (The Siege of Syracuse, Roma Nova, Time Mesh, High Tea), architectural/natural heritage awareness (Travel in Europe, VE-Game, O' Munaciedd, Tidy City) and artistic/archaeological heritage awareness (Tate Trumps, Thiatro, Time Explorer, Dessine-moi un Mammouth).

perform tasks like shooting or avoiding obstacles, mechanics which are hardly related to cognitive gain, but can be included as sub-tasks or mini-games for the sake of engagement. This is the case of Streets of Culture and Ancient Olympia, including respectively driving and sport sessions. The mini-games in Multi-touch rocks can be considered action games as well. However, in this kind of gameplay the learning content is relatively low, and games tackle primarily engagement rather than actual cognitive gain.

Strategy games adopt a gameplay requiring careful and skilful thinking and planning in order to achieve victory (The Battle of Waterloo and 1066). However, this genre is suitable to raise awareness about the complexity of tactical thinking rather than actually teach or train such skills.

Very close to strategy games are simulation games, generally designed to simulate aspects of a real or a fictional reality. Simulation games include several sub-categories like vehicle simulators; however, among the reviewed games we found only instances of the so-called construction and management simulators, based on building, expanding or managing fictional communities or activities with limited resources. The simulation mechanism is the best suited to make the player appreciate the consequences of his/her decisions (e.g. History Canada, Building Detroit). Together with roleplaying adventure games, simulations are also widely adopted for raising awareness about affective and moral-related issues for the powerful sense of empathy they are able to evoke. Indeed, the player slips in another skin and lives in first person difficulties or injustices (e.g. Real Lives, Expedition Africa). The evaluation of High Tea [11], for instance, reports that, while the game was primarily intended as an advert for the corresponding real exhibition, players became accidentally aware about the anti-moral behaviour of the British Empire during the opium war, and were quite critical and surprised (someone nearly shocked) by this understanding.
Trivia games are usually in the form of questions and answers and the player is supposed to learn (or to trigger his/her interest about a topic or to become aware of something) from the additional information provided by the game after his/her guess (e.g. The China Game, My Culture Quest).

Puzzle games work solving logic puzzles, or navigating mazes, or matching tiles. Puzzles are well suited to be played on mobile devices, and this is reflected by the fact that all the reviewed games for augmented visits are indeed puzzle games. Moreover, we note that all the serious games for architectural and natural heritage are puzzles or at least include puzzles (Travel in Europe). Other puzzles are either static in-museum application, so that the gameplay must be easily comprehensible and the game session is supposed to be short due to time and space constraints (e.g. History of a Place), or are deployed on-line nearly as casual games, mainly to raise awareness about the host web site (see, for instance, the Getty Museum website: http://www.getty.edu/gettygames/).

Adventure games started in the 1970s when the interaction was purely textual, through the prompt. Over time graphics have been introduced to the genre and the interface has evolved. Now 2D point-and-click adventures consumed over the browser are quite common in the heritage sector (e.g. Time Mesh) as well as 3D real time adventures (e.g. Icura). The gameplay in adventure games do not require reflex challenges or action; conversely, various puzzles must be solved by collecting, combining and using objects and interacting with people in the environment.

Adventure games are particularly suited to implement the "learning by doing" approach, which is related to the constructivism theory [24], where the player learns by constructing knowledge while doing a meaningful activity. In this approach to education the learner does not passively receive information but rather actively constructs new knowledge by finding information in 
the game, understanding it and then applying the new knowledge to fulfill tasks. As underlined in Froschauer [25], players remember more the knowledge related to task completion than information directly provided by the game.

Fig. 2 shows how the different educational objectives are related to game genres.

\section{Contexts of use of serious games for heritage}

Serious games for heritage are deployed both in formal and informal contexts and can be played at home, in a public place, visiting a city, or at school. Such different contexts of use cast specific technological and methodological requirements on the game design. In this section, we will discuss the issues, the adopted solutions or the suggested guidelines in order to produce effective serious games for heritage in three different cases: the static setup in a public space such as at the museum; the augmented visit (indoor, as at an exhibition or outdoor, as visiting a city) requiring mobile devices; and the stand alone application for deployment at home or at school.

As for the game settings of use, the designer has to distinguish a game primarily designed for non-public settings from a game for a public space. A game for home use can be more complex because the user has more time to learn the game goals and mechanics. A game installed in a static location - typically along the path of a public exhibition - is likely to have strict space and time constraints. Thus, the gameplay should be immediate, with no need for tutoring [26] in order to avoid creation of visitors' queues. An example is History of a place, a set of simple puzzles linking to additional text and images, which visitors of the Messenia museum can play in single-player mode. A multi-player architecture allows several visitors to play simultaneously (e.g. Siege of Syracuse, The Battle of Thermopylae). Exhibitions usually address a larger number of players at the same time. In such a case, the game can be designed for players to join, play a short game and then leave at any time. The recommendations for such kind of games have been summarized by Cao et al. [27]: be casual and lightweight; be simple to understand and operate; be suitable for various populations; implement ad-hoc joining and leaving mechanisms and encourage group play and communication. An example is Multi-touch rocks, which runs on a multi-touch table allowing several players to join seamlessly.

The multi-player experience reaches its maximum extent where a very large number of people can take part in the experience, like in a dome. Thanks to the available technology, it is possible to generate a graphically rich and immersive virtual reality; the session can be much longer even if the mechanics cannot be complex. In this case, the biggest challenge regards the interaction between the application and such a high number of players. Usually the system manages input from controls placed in the seats of the theatre, or a facilitator actually controls the game upon the audience suggestions. However, the technological set-up is complex and expensive [28].

Differently from static installations in public settings, games for cultural tourism and augmented visits (of cities, natural landscapes, archaeological locations, museums, etc.) are designed to augment a real experience and engage players with the cultural content encountered along their tour. The last generation personal devices like smartphones perfectly adapt to these scenarios. On the one side, such tools are more and more popular, the majority of visitors have one, so that museums do not need to account a budget for additional technical equipment (e.g. Tate Trumps). On the other side, they provide an ubiquitous link between real and virtual environment - a tourist can enter/quit the game during the real tour of a city whenever he/she has the opportunity (e.g. Tidy City,
VeGame)- and enrich the real experience with social mechanisms, e.g. the tourist can live a collective cultural experience where players share common objectives for a cultural purpose. Players can also reference cultural artefacts in situ, allowing for the superimposing of design elements like ancient buildings onto images or objects in real world locations (MediaEvo, À la recherche de l'empreinte perdue). Trivia and puzzle games are the most popular in this context, especially in the form of treasure hunts: the gameplay can have one or more players trying to find hidden articles, locations or places by using a series of clues as an indoor or outdoor activity.

Some other games offer a completely virtual tourism experience. Games for virtual tourism require an immersive experience given by realism in the environment and in the navigation (e.g. Travel in Europe). Virtual museums are not simply virtual replicas of a real counterpart: in many cases, they integrate affine objects which in reality reside in different locations (e.g. Discover Babylon), or permit to create dynamically a personalized experience generating new collections according to the user's interests (e.g. Thiatro). But the real challenge for a virtual museum is engaging the visitor and raising emotions, which supplement the real visit: indeed, virtual tourism and virtual museum games can be played before or after the real experience. According to professionals in the sector, there is evidence that a previous virtual experience helps visitors understanding and engaging more in a following real visit. Many museums in North America are heavily investing on their web sites, adding multimedia and games to engage audiences and attract more visitors to the physical museum [29]: for instance, the Mount Vernon Estate and Gardens with George Washington's World for Kids or the Canadian museum of Quebec with Fascinating Egyptian mummies. A few, in Europe, are creating on-line games to raise interest about the museums and advertise upcoming exhibitions, e.g. the British Museum with Time Explorer.

Except for games located in exhibitions or designed as mobile applications for augmented visits, all the other games can be consumed at home or at school, or both: a game can even be played partially at school, in small groups and with the support of the teacher, and partially at home. For integration in the formal education contexts, the main issue is the adherence to the national curricula. Then, there are practical issues related to the school policy with respect to installing new software and to the availability of support material to help students in the learning but also teachers in structuring their lessons and in testing the knowledge gained through the game. A significant example in this regard is represented by Playing History due to both the good game design and the valuable learning material provided. In fact, the design has been grounded on accredited pedagogical theories for the formal education context and the suggested lesson plan is based on an experience-oriented approach inspired by David A. Kolb's theory of learning [30]. As a result, the game is largely diffuse: in fact, it has been adopted by more than 70 schools only in Denmark.

In games for formal education, adaptation to the student level is also essential. We have found just one example of adaptive game, i.e., 80DAYS, where user actions, timings, correctness of answers, sequences are tracked and evaluated. Based on recommendations coming from an e-Learning engine, game flow and mechanics are modified to fit the player's profile. This might be the right way to go to face this issue.

In Fig. 3, a summarising chart with the application contexts with respect to educational objectives is presented.

\section{Creating an engaging learning environment}

On the basis of the conducted analysis, we have singled out two main factors as key for serious game effectiveness: an appealing 


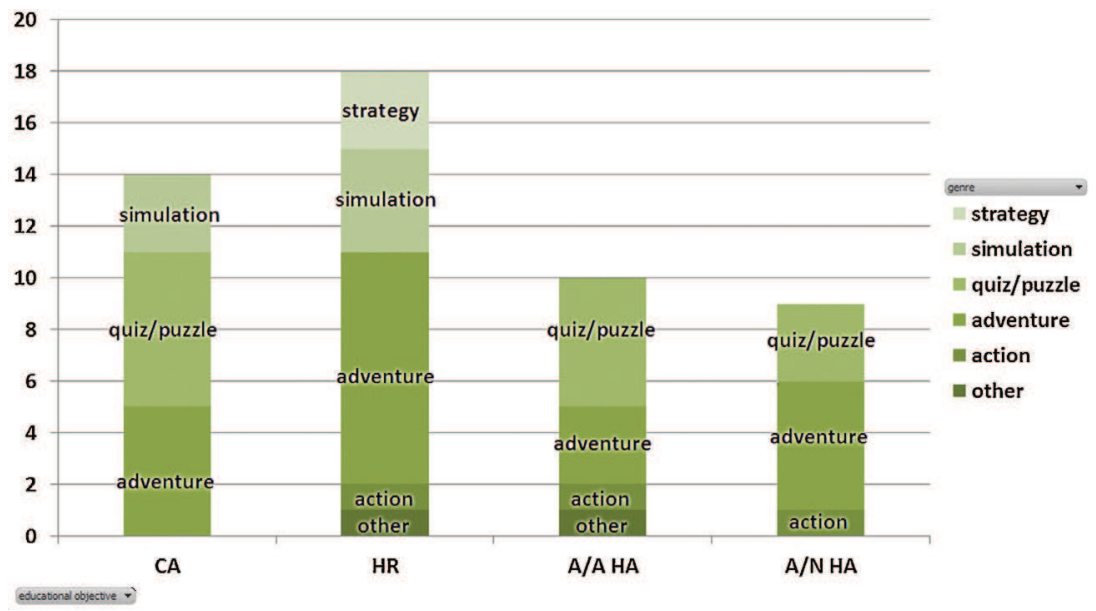

Fig. 2. Chart of the reviewed serious games (SGs) for cultural heritage according to the primary learning objective and the game genre, where $\mathrm{CA}=$ cultural awareness; $\mathrm{HR}=$ historical reconstruction; $\mathrm{A} / \mathrm{A} \mathrm{HA}=$ artistic/archaeological heritage awareness; $\mathrm{A} / \mathrm{N} \mathrm{HA}=$ architectural/natural heritage awareness.

and meaningful environment and a suited and intuitive interaction paradigm.

Since 2000, a greater attention has been paid to the graphical aspects and the most recent SGs appear as real games rather than just educational tools with a weak game dressing. The choice of 2D or $3 \mathrm{D}$ settings in a serious game depends on many factors, including the target users and the market to be addressed. As seen in the previous sections, a 3D setting is not necessary in trivia and standard puzzle games (among the 14 puzzle games we reviewed, 50\% use 2D graphics, $43 \%$ are based on text and multimedia and only one is set in 3D). Conversely, many of the recent adventure games are set in 3D environments (the $64 \%$ of the 22 reviewed games). In fact, games which naturally involve exploration/navigation actions (like in historical reconstructions and virtual tourism) are preferably set in 3D to be closer to real life. Moreover, the technological advancement has made the use of 3D affordable on standard PCs and now also on the web thanks to the diffusion of plugins (e.g., Unity Web player, Flash 3D) and new web standards (e.g., webGL, HTML 5). The adopted platforms are mainly PC (41\%), browser (37\%) and mobile (12\%) with a few multi-platform games or requiring ad-hoc set-ups. Browser games are mainly 2D-based on Flash, while PC games are mainly 3D developed using the popular game engines Torque and Unity3D.

In general, the content is created using standard 3D modelling software or by a 3D reconstruction from real data; procedural modelling is sometimes applied to create automatically realistic environments such as cities [31,32]; in virtual tourism applications like Travel in Europe realism is enhanced through the geo-referencing. Animations can be created synthetically with semi-automatic tools for single and crowd animations, but also through motion capture techniques able to acquire real and natural movements [33].

3D settings are able to support situated cognition by offering a realistic/meaningful environment where the learning process can effectively be situated [34] also giving to the player the possibility of interacting with objects in their actual context [16]. Realistic 3D environments offer the player the possibility of immersing in realistic reconstructions of events and context, thus facilitating learning, in particular in historical awareness games. For instance, the understanding of the evolution of a battle can be improved by knowing and dealing with the morphology of the surrounding environment (The Battle of Thermopylae).

In virtual tourism applications, not only the environment represents the context where the learning process takes place, but also is the learning content itself. The gameplay most suitable for 3D environments seems to be the open-ended (or "sandbox") gameplay. From the pedagogical point of view, sandbox serious games are organized such that they support players in building a suited knowledge structure for the addressed topics.

Virtual museum and virtual tourism games can benefit from faithful reconstructions of 3D objects or buildings of interest (e.g. Discover Babylon). The presence of virtual 3D content makes the experience interesting and informative similarly to the real counterpart: in fact, the visitor can manipulate, rotate, enlarge precious objects with no risk of damage, and even when the artefacts are not intrinsically three dimensional, a 3D environment provides a

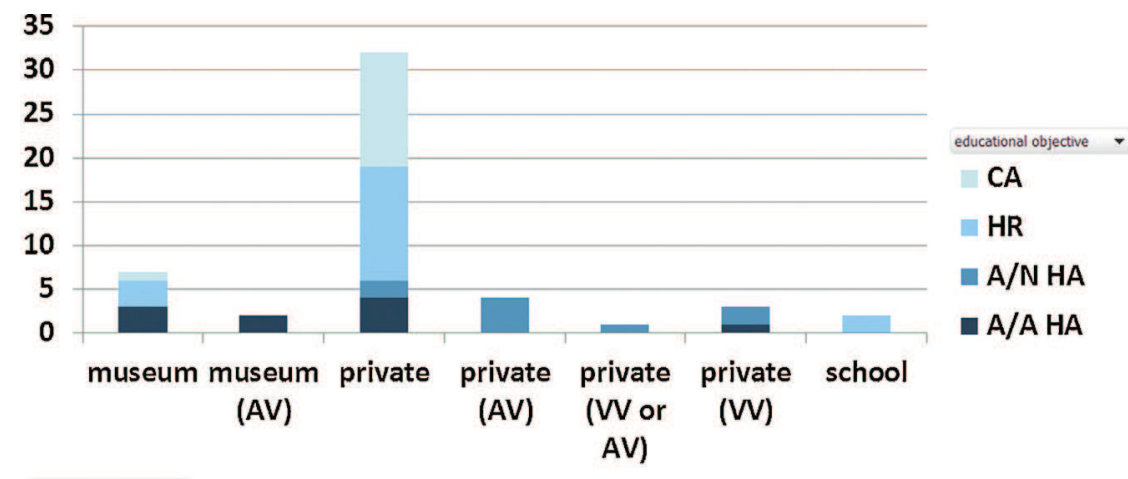

Fig. 3. Game application contexts with respect to educational objectives. 
concrete reference where the learning content is organized [17]. In any historical reconstruction, the presented data must be accurate and the main cultural artefacts faithfully represented. Historical accuracy is clearly crucial and difficult to achieve, especially when dealing with incomplete, deteriorated or missing remains or incomplete information. Therefore, collaboration between the game designers and historians is fundamental to develop a wellfounded serious game in the field.

Where relevant (e.g. in augmented reality applications), a link to the real remains/objects should be kept to show the context and increase the available (multimedia) information.

Beside the realism, also the emotional involvement is frequently employed. For instance, for raising awareness about the problematic conditions of a population, a crucial aspect is the ability of evoking a feeling of empathy with the characters in the game (e.g. AfricaTrail).

The second key factor to consider for proper SG design concerns user interaction modalities. Games are increasingly being played on-line (on the browser) and/or on mobile devices (especially for augmented cultural visits). While the majority of games are still based on keyboard/mouse interaction, mobile applications typically feature images, SMS (e.g. Tidy City), bar-codes and QR codes (e.g. Muse-Us). Actually, games on mobile devices have a great potential to engage museum visitors. One popular type of game in this perspective is "location-gaming": the mechanics is that players go to places, do fast, simple tasks (like typing something into their phone, or uploading a photo of something), and win a reward (either virtual points or something tangible). The leading platform for location-gaming is SCVNGR ${ }^{43}$, a free application for iPhone and Android that has already been adopted by several cultural institutions. SCVNGR uses the GPS embedded in the smartphone to verify a user's location in the real world. Interactive exhibitions for cultural heritage often use specific hardware, like multi-touch tables (Multi-touch rocks), haptic devices (Gargas caves), caves and domes (Ancient Olympia), which clearly involve dedicated HPC systems. Dehais et al. [23] observe that the use of touch displays in public institutions (e.g. museums) is a common practice and that interactive displays in exhibitions encourage a collaborative atmosphere. $\mathrm{HCI}$ devices emerge especially in games for archaeology, e.g. the Multi-touch Rocks and the Gargas caves - Dessine-moi un Mammouth [34].

Regarding interaction paradigms in general, the trend seems to be towards as-natural-as-possible interactions like tactile ones $[34,35]$, even if customers seem still happy with the traditional mouse/keyboard devices. Indeed, other emerging means like gesture recognition and the multi-modal interactions offered by the low-cost kinect devices appear very promising [36] because of the natural interaction supported, which allows the player to use his/her entire body to interact, thus enhancing usability and motivation because of the huge feeling of embodiment (e.g. MediaEvo).

\section{Conclusions}

In this paper we have presented a broad state-of-the-art of serious games for cultural heritage, highlighting the educational objectives of games in this domain and analysing the complex relations between genres, contexts of use, technological solutions and learning effectiveness.

Analysing the state-of-the-art, we have singled out some overall challenges and open issues that should be addressed by the research in order to improve the quality of SGs and their benefits for users and stakeholders.

43 http://www.scvngr.com/.
Regarding game design, research efforts should be planned in the direction of a smarter management and provision of multimodal and multidimensional content. Games for cultural heritage often include additional multimedia content that aim at providing more in-depth information (e.g., History of a Place, Africa Trail, Expedition-The Game, and others). Adoption of semantics and integration of web2.0 technologies within a game could be envisaged in this regard, as suggested by the preliminary results of MOSAICA [5].

With respect to in-museum games, we have seen that multiplayer architectures or dedicated interactive shows are able to engage a large audience, overcoming time and space limitations. A challenge here is to move from a mass-oriented approach towards a personalized experience even through a single application able to adapt to a wide variety of user profiles. The use of proper interaction devices may also help in this direction.

Concerning the learning aspect, Bloom's taxonomy $[37,38]$ identified three main types of goals of the learning process: cognitive, psychomotor, and affective, that is, after a learning episode, the learner should have acquired new knowledge, skills, and/or attitudes. More comprehensive tests are needed to understand better what game mechanics should be implemented in order to target higher learning levels in the Bloom's cognitive taxonomy. A recent overview performed in the broader field of SGs for learning confirms this conclusion [39]. These considerations also highlight the need for user assessment methodologies able to really understand the user knowledge level and progress. This will be useful not only for provision of formative feedback and support of adaptation, but also to provide proper evidence of a SG effectiveness: the lack of formal evidence of learning gain is still perceived as the main barrier to a wider SG adoption.

We believe that SGs for cultural heritage are particularly suited with respect to the affective domain. Empathy with a game character and plot may be very helpful for understanding historical events, different cultures, other people's feelings, problems, and behaviours, on the one hand, and the beauty and value of nature, architecture, art and heritage, on the other one. This persuasive approach should clearly be combined with the rigour of the scientific method, which is a balance not easy to achieve, not only in games.

Finally, the design of a SG, by its nature, requires the iterative collaboration of various experts with specific competences and skills: educators, art directors, game designers, scriptwriters, software developers, graphic and sound designers. Additionally, a $\mathrm{SG}$ in the $\mathrm{CH}$ field cannot ignore the domain experts who select the educational contents and the content providers, who can have additional aims beyond education, as for instance scientific validity and reliability. This teamwork aims at preventing the final SG from being just a game with an extra layer of pedagogical content. Unfortunately, small developer enterprises cannot usually count on all such experts and then the design choices and verifications are usually made without the proper knowledge and awareness. We believe that the new curricula for MSc and PhD courses on serious games should be able to shape this kind of new interdisciplinary professional profiles.

\section{Acknowledgments}

This paper has been partially supported by the EU NoE "GALA: Games and Learning Alliance", contract no. 258169, FP7ICT-2009.4.2.

\section{References}

[1] B. Capdevila, B. Marne, J.M. Labat, Conceptual and Technical Frameworks for Serious Games, in: Proc. 5th European Conference on Games Based Learning Academic Publishing Limited, Reading, UK, 2011, pp. 81-87. 
[2] E. Falk Anderson, L. McLoughlin, F. Liarokapis, C. Peters, P. Petridis, S. de Freitas, Developing serious games for cultural heritage: a state-of-the-art review, Virtual Real. 14 (4) (2010) 255-275.

[3] J. Froschauer, I. Seidel, M. Gartner, H. Berger, D. Merkl, Design and evaluation of a serious game for immersive cultural training, in: Proc. 16th International Conference on Virtual Systems and Multimedia (VSMM), 2010, pp. 253-260.

[4] C. Huang, Y. Huang, Annales school-based serious game creation framework for Taiwan indigenous cultural heritage, ACM J. Comput. Cult. Herit. 6 (2) (2013) (special issue on serious games for cultural heritage. To appear).

[5] 6th EU Framework Program-IST-034984 MOSAICA - Semantically enhanced, multifaceted, collaborative access to cultural heritage.

[6] D. Christopoulos, P. Mavridis, A. Andreadis, J.N. Karigiannis, Using virtual environments to tell the story: The battle of Thermopylae, in: Proceedings of VS-Games 2011, 2011.

[7] D. Christopoulos, A. Gaitatzes, Multimodal interfaces for educational virtual environments, informatics, 2009. PCI '09. 13th Panhellenic Conference on (2009) 197-201.

[8] A. Gaitatzes, D. Christopoulos, G. Papaioannou, The Ancient Olympic Games: Being Part of the Experience, in: in Proceedings of the 5th International Symposium on Virtual Reality, Archaeology and Intelligent Cultural Heritage VAST, 2004, pp. 1-10.

[9] A. Doulamis, F. Liarokapis, P. Petridis, G. Miaoulis, Serious games for cultural applications, in: D. Plemenos, G. Miaoulis (Eds.), Artificial Intelligence Techniques for Computer Graphics, Springer, 2011.

[10] R. Francis, Revolution, learning about history through situated role play in a virtual environment, in: Proc. of the American educational research association conference, 2006

[11] D. Birchall, M. Henson, Hig Tea Evaluation Report, Wellcome Trust, August 2011 (http://museumgames.pbworks.com/w/file/fetch/44614076/ HighTeaEvaluationReport.pdf).

[12] F. Bellotti, R. Berta, A. De Gloria, A. D’Ursi, V. Fiore, A serious game model for cultural heritage, ACM J. Comput. Cult. Herit. 5 (4) (2012) 2012.

[13] F. Bellotti, R. Berta, A. De Gloria, S. Cardona, An architectural approach to efficient 3D urban modeling, Comput. Graph. 35 (5) (2011) 1001-1012.

[14] L. T. De Paolis, G. Aloisio, M.G. Celentano, L. Oliva, P. Vecchio, MediaEvo project: a serious game for the edutainment, Computer Research and Development (ICCRD), 2011 3rd International Conference on, vol. 4 (2001) 524-529.

[15] F. Bellotti, R. Berta, E. Ferretti, A. DeGloria, M. Margarone, VeGame: field exploration of art and history in Venice, IEEE Comput. (2003) (Special issue on Handheld Computing).

[16] J. Froschauer, M. Arends, D. Goldfarb, D. Merkl, Towards an Online Multiplayer Serious Game Providing a Joyful Experience in Learning Art History, Proceedings of the Third International Conference on Games and Virtual Worlds for Serious Applications (VS-GAMES), 2011

[17] J. Froschauer, D. Merkl, M. Arends, D. Goldfarb, Art history concepts at play with ThIATRO, ACM J. Comput. Cult. Herit. 6 (2)(2013) (special issue on serious games for cultural heritage. To appear).

[18] L. Minett, C. Gavin, "The Middleton Mystery: an adventure at Belsay Hall" interpreting heritage through the design and development of a computer game, Proceedings of Electronic Visualisation and the Arts (EVA 2008), London, UK (2008).

[19] M. Spaniol, Y. Cao, R. Klamma, P. Moreno-Ger, B. Fernández-Manjón, J.L. Sierra, G. Toubekis, From Story-Telling to Educational Gaming: The Bamiyan Valley Case, Proceedings of the 7th International Conference on Web-based Learning (ICWL 2008), Jinhua, China. Lecture Notes in Computer Science 5145, (2008) 253-264

[20] C. Tanguy, MuseUs: case study of a pervasive cultural heritage serious game, ACM J. Comput. Cult. Herit. 6 (2) (2013) (special issue on serious games for cultural heritage. To appear)
[21] Y. Cao, R. Klamma, M. Jarke, The Hero's Journey - template-based storytelling for ubiquitous multimedia management, J. Multimedia 6 (2) (2011) 156-169 (Special Issue. Academy Publisher).

[22] E. Gadolou, H. Papadaki, E. Stefanakis, G. Kritikos, Y Cao, A. Hannemann, R Klamma, D. Kovachev, Storytelling, Spatial Standards and Cultural Heritage Management, in: M. Painho, M. Yasmina Santos, H. Pundt (Eds.), Proceedings of 13th AGILE International Conference on Geographic Information Science, Geospatial Thinking, Guimaraes, Portugal, 2010.

[23] C. Dehais, V. Charvillat, J. Conter, Interactive augmentation of photographs depicting prehistoric engravings, in: Proceedings of EUROSIS, 2007, pp. 74-80.

[24] E. Glaserfeld, Constructivism in education, Pergamon Press, Oxford England, 1989.

[25] J. Froschauer, Serious Heritage Games: Playful Approaches to Address Cultural Heritage, PhD Dissertation, Faculty of Informatics, Vienna University of Technology, May 2012.

[26] M. Seidl, P. Judmaier, F. Baker, U. Egger, N. Jax, C. Weis, M. Grubinger, G. Seidl, Multi-touch Rocks: Playing with Tangible Virtual Heritage in the Museum - First User Tests, in Proceedings of VAST: International Symposium on Virtual Reality, Archaeology and Intelligent Cultural Heritage - Short and Project Papers, (2011) 73-76.

[27] X. Cao, M. Massimi, R. Balakrishnan, Flashlight jigsaw: an exploratory study of an ad-hoc multi-player game on public displays, in: Proceedings of the 2008 ACM Conference on Computer supported cooperative work, New York, NY, USA, 2008, pp. 77-86

[28] D. Christopoulos, P. Apostolellis, A. Onasiadis, Educational Virtual Environments for Digital Dome Display Systems with Audience Participation, Proceedings of the 13th Panhellenic Conference in Informatics - Workshop in Education, Corfu, Greece, (2009) 265-275.

[29] http://futuresoflearning.org/index.php/Firda_08/tag/games+in+museums

[30] D. Kolb, Experiential learning: experience as the source of learning and development. Englewood Cliffs, Prentice Hall, New Jersey, 1984.

[31] S. Haegler, P. Mueller, L. Van Gool, Procedural modeling for digital cultural heritage, EURASIP J. Image Video Process. (2009) (article ID 852392).

[32] J. Togelius, J. Whitehead, R. Bidarra, Procedural content generation in games, IEEE Trans. Comput. Intell. AI Games 3 (3) (2011) 169-171.

[33] D. Thalmann, H. Grillon, J. Maim, B. Yersin, Challenges in Crowd Simulation, nternational Conference on Cyberworlds (CW 2009), Bradford, England, 2009.

[34] D. Djaouti, J. Alavrez, O. Rampenoux, V. Charvillat, J.P. Jessel, Serious games \& cultural heritage: a case study of prehistoric caves, in: Proc. 15th International Conference on Virtual Systems and Multimedia (VSMM “09). IEEE Computer Society, Washington DC, USA, 2009, pp. 221-226.

[35] S. Arnab, P. Petridis, I. Dunwell, S, de Freitas, Tactile interaction in an ancient world on a web browser, Int. J. Comput. Inform. Syst. Ind. Manage. Appl. 3 (2011) 687-695.

[36] H. Richards-Risseto, J. Robertsson, J. Von Schwerin, G. Agugiaro, F. Remondino, G. Girardi, M. Forte, Hands-Off: using Kinect to virtually query the ancient Maya city of Copan, Honduras, in: Computer Applications and Quantitative Methods in Archaeology (CAA), Southampton, UK, 2012.

[37] B.S. Bloom, M.D. Engelhart, E.J. Furst, W.H. Hill, D.R. Krathwohl, Taxonomy of educational objectives: the classification of educational goals, Handbook I. Cognitive Domain, Longmans, Green, New York, 1956.

[38] L. Anderson, D.A. Krathwohl, Taxonomy for Learning, Teaching and Assessing: A Revision of Bloom's Taxonomy of Educational Objectives, Longman, New York, 2001

[39] T.M. Connolly, E.A. Boyle, E. MacArthur, T. Hainey, J.M. Boyle, A systematic literature review of the empirical evidence on computer games and serious games, Comput. Educ. 59 (2) (2012) 661-686. 